\title{
Effect of Replanting Zinnia Plants for Remediation of Oil-Contaminated Soil
}

\author{
Makoto Mita $^{1 *}$, Hiromi Ikeura $^{2}$, Takamitsu $\mathrm{Kai}^{1}$, and Masahiko Tamaki ${ }^{1}$ \\ ${ }^{1}$ School of Agriculture, Meiji University, 2060-1, Kurokawa, Asao-ku, Kawasaki, Kanagawa, Japan \\ ${ }^{2}$ Faculty of Life and Environmental Science, Shimane University, 1060, Nishikawatsu, Matsue, \\ Shimane, Japan
}

\begin{abstract}
Previously, we demonstrated that the zinnia plant was effective for the phytoremediation of oil-contaminated soils and that it had a higher remediation effect during the initial growth period. Therefore, repeated planting of zinnia for the initial growth period might enhance the remediation of contaminated soils, so we performed the following study. Seeds were sown in soils containing $4 \%(\mathrm{w} / \mathrm{w})$ diesel oil and grown for 100 days. We carried out two treatments: replanted plots where aboveground parts of plants were cut after 50 days, and new seeds were sown; or non-replanted plots where plants were allowed to grow for 100 days. The soil dehydrogenase activity and soil total petroleum hydrocarbon concentrations were analyzed. At the end of the study, no significant differences were found between replanted and non-replanted plots for either measurement. Therefore, replanting did not affect remediation. Degradable oil components in the soils may have been degraded in the initial growth period of the first planting, but by the time of replanting there may have been few degradable oil components left in the soil, so there was no beneficial effect of replanting. We concluded that replanting is unsuitable for phytoremediation of oil-contaminated soils.
\end{abstract}

\section{Introduction}

Petroleum is essential for daily life in most societies. However, petroleum flowing into the soil because of mining, transportation, and leakage causes serious ecological catastrophes $[1,2]$. Among various soil remediation methods, processes using plants (phytoremediation) have been recognized as a cost-effective method to treat oil polluted soils and sediments [3]. Compared with physicochemical methods such as excavation removal, pyrolysis, and contaminated water extraction, phytoremediation is simple and easy to operate, and can be done in the original place that is contaminated. In addition, using ornamental flowering plants has advantages such as improving the landscape, dispelling the negative image of the contaminated area, and being a potential source of commercial revenue. In our previous study, we used 33 species of ornamental flowering plants and found that genus Zinnia produced the highest oil degradation ability, especially during their initial growth period

\footnotetext{
* Corresponding author: win0use.nkfastap@gmail.com
} 
[4]. Therefore, repeated planting of zinnia to maximize the initial growth period (i.e., cutting above-ground parts from the root after the initial growth period and replanting) may enhance phytoremediation of contaminated soils. In this manuscript, we demonstrated the influence of growth period and replanting of zinnia on degradation effects in soils contaminated by diesel oil. We thus aimed to identify the most efficient degradation method.

\section{Materials and methods}

\subsection{Preparation of oil-contaminated soil}

Oil-contaminated soil was treated according to the method of Kaimi et al. [5]. Commercial andosol was purchased and air-dried for two weeks in a greenhouse. The chemical properties of the soil were determined as follows: $\mathrm{pH} 6.7$ and electric conductivity $0.120 \mathrm{dS} / \mathrm{m}$. After two weeks of air-drying, the soil was passed through a $2-\mathrm{mm}$ sieve to remove roots and stone residues and homogenize the soil. The soil was gradually mixed with diesel oil ( $4 \%$ by weight) while stirring with a mechanical mixer to ensure uniform mixing. The contaminated soil was stirred once every two days for 14 days to volatilize the remaining oil particles in the greenhouse [2]. Initial Total petroleum hydrocarbon (TPH) concentration was $33,513 \pm 767 \mathrm{mg} / \mathrm{kg}$. Non-contaminated soil was treated using the same method without adding diesel oil.

In our previous study (data not shown), we determined that zinnia plants could not grow at diesel oil concentrations $>4 \%$ by weight. LPG and gasoline are highly volatile and using them would impede reproducible experimental conditions and thus affect results. Furthermore, lubricating oil contains various additives which could affect the growth of microorganisms and plants. On the other hand, diesel oil is less volatile and does not contain various additives; hence, using diesel oil facilitated reproducibility of experiments, and diesel oil is suitable for tracking microbial behavior.

\subsection{Remediation and treatments using plant species}

Table 1. Treatments

\begin{tabular}{llll}
\hline Plots & 0 DAS & 50 DAS & 100 DAS \\
\hline Non-cultivation $(\mathrm{E})$ & Non-sown & Analyzed \\
Cultivation and replanted $(\mathrm{R})$ & Sown & $\longrightarrow$ Cut \\
Cultivation and non-replanted $(\mathrm{P})$ & Sown & Sown $\longrightarrow$ Analyzed \\
\hline
\end{tabular}

Table 2. Treatment details

\begin{tabular}{lcc}
\hline \multirow{2}{*}{ Plots } & $\begin{array}{c}\text { Non-contaminated soil } \\
(\mathrm{N})\end{array}$ & $\begin{array}{c}\text { Contaminated soil } \\
(\mathrm{O})\end{array}$ \\
\hline Non-cultivation $(\mathrm{E})$ & $\mathrm{N}-\mathrm{E}$ & $\mathrm{O}-\mathrm{E}$ \\
Cultivation and replanted (R) & $\mathrm{N}-\mathrm{R}$ & O-R \\
Cultivation and non-replanted $(\mathrm{P})$ & $\mathrm{N}-\mathrm{P}$ & $\mathrm{O}-\mathrm{P}$ \\
\hline
\end{tabular}


The plant used in this study was zinnia (Zinnia hybrida cultivar, Profusion White) (Sakata Seed Corporation, Yokohama, Japan). In a previous study, it was reported that Profusion White has the highest growth and remediation rates in oil-contaminated soil among Z. hybrida varieties [6].

Six treatments are shown in Tables 1 and 2. Two hundred grams of oil-contaminated soil $(\mathrm{O})$ or non-contaminated soil $(\mathrm{N})$ were placed in vinyl pots $(10 \mathrm{~cm}$ diameter $\times 8.5 \mathrm{~cm}$ height) and mixed $2.4 \mathrm{~g}$ of a commercial compound solid fertilizer $\left(\mathrm{N}: \mathrm{P}_{2} \mathrm{O}_{5}: \mathrm{K}_{2} \mathrm{O}: \mathrm{Mg}=\right.$ 6\%:40\%:6\%:15\%). Then, 10 seeds were sown in cultivation and replanted plots (R) or cultivation and non-replanted plots $(\mathrm{P})$ pots. Seeds were not planted in the non-cultivation plots (E).

The experiment was conducted in the growth chamber (MLR-351H, SANYO Electric Co., Ltd., Osaka, Japan) under a 12-h light/dark cycle at $25^{\circ} \mathrm{C}$ for 100 days. Photosynthetic photon flux density of light was $\sim 150 \mu \mathrm{mol} / \mathrm{m}^{2}$ s. After emergence, the seedlings were thinned to three per pot. Fifty days after sowing (DAS), the above-ground parts of the plants in R plots were cut, new seeds were sown, and seedlings were thinned. All pots were eqaully irrigated daily with $30 \mathrm{~mL}$ water. Once every week, $30 \mathrm{~mL}$ of 500 -fold diluted commercial liquid fertilizer $\left(\mathrm{N}: \mathrm{P}_{2} \mathrm{O}_{5}: \mathrm{K}_{2} \mathrm{O}=6 \%: 10 \%: 5 \%\right)$ was provided instead of water. Destructive sampling was performed three times using four pots per treatment, at 50-day intervals (up to 100 days).

\subsection{Plant analysis}

Plants grown in R and P plots were harvested and analyzed at 50 and 100 DAS. Plant flowering number and plant height was measured for three plants per pot. The dry weights of shoots and roots were measured after carefully rinsing with water and oven drying them for four days at $80^{\circ} \mathrm{C}$.

\subsection{Soil analysis}

Soil DHA was measured according to the method of Hayase [7]. Each soil sample $(1 \mathrm{~g})$ was placed in a test tube and added to $1 \mathrm{~mL}$ of $0.25 \mathrm{mmol}$ tris-hydrochloric buffer solution ( $\mathrm{pH}$ 6.8), $200 \mu \mathrm{L}$ of $0.4 \%$ 2-(4-iodophenyl)-3-(4-nitrophenyl)-5-phenyl tetrazolium chloride, and $50 \mu \mathrm{L}$ of $1 \%$ glucose and incubated at $30^{\circ} \mathrm{C}$ for $24 \mathrm{~h}$ in the dark. The iodonitrotetrazolium formazan produced was extracted using $10 \mathrm{~mL}$ of methanol, and its absorbance was determinedusing a spectrophotometer (UV-1700, Shimazu Corporation, Kyoto, Japan) at $485 \mathrm{~nm}$. All measurements were performed in triplicate.

TPH concentration was determined following the method of the Ministry of the Environment in Japan issued in guidelines to prevent oil pollution [8]. Each soil sample without root segments was homogenized and stored at $30^{\circ} \mathrm{C}$ for four days to ensure dehydration. Then, $15 \mathrm{~mL}$ of carbon disulphide was added to $5 \mathrm{~g}$ of soil samples as the extraction solvent in 50-mL erlenmeyer flasks. The mixture was extracted by shaking for $30 \mathrm{~min}$. The mixture was then allowed to stand for $2 \mathrm{~h}$ and the supernatant was recovered. In the second and third rounds, the same procedure was performed by changing the settling time to $1 \mathrm{~h}$ and the supernatant was diluted in a measuring cylinder to $50 \mathrm{~mL}$ in total. The supernatant was filtered using a membrane filter (pore diameter $0.45 \mu \mathrm{m}$ ), and then injected into a gas chromatograph hydrogen flame ionization detector (GC-FID, GC-2010, Shimazu Corporation, Kyoto, Japan). Helium was used as the carrier gas and $1 \mu \mathrm{L}$ of the extracted sample was injected using an auto-injector (AOC-20i, Shimazu Corporation, Kyoto, Japan). The settings of GC-FID were as follows: the inlet and detector temperatures were $320^{\circ} \mathrm{C}$, the temperature program was maintained at $35^{\circ} \mathrm{C}$ for $5 \mathrm{~min}$ and increased to $320^{\circ} \mathrm{C}$ at $10^{\circ} \mathrm{C} / \mathrm{min}$, the column was a capillary column (Intercap $1 \mathrm{MS}$, GL Science Inc., Tokyo, 
Japan), the liquid phase was 5\% phenyl methyl silicone, the length was $30 \mathrm{~m}$, the inner diameter was $0.32 \mathrm{~mm}$, and the film thickness was $0.25 \mu \mathrm{m}$.

\subsection{Statistical analysis}

Data were collected as mean values of four replicates and analyzed using Excel Statistics 2012 for Windows (Social Survey Research Information Co., Ltd., Tokyo, Japan). Plant height, shoot, and root dry weights and flowering number between non-contaminated and contaminated soils in each treatment were determined using the Welch's t-test. Soil DHA values and soil TPH concentrations were analyzed between treatments using a one-way ANOVA followed by a Tukey's multiple comparisons test. Differences were considered significant at $\mathrm{P}<0.05$.

\section{Results}

Table 3. Transition of plant height and dry weight of Zinnia hybrid 'Profusion White'

\begin{tabular}{|c|c|c|c|c|c|c|c|c|c|}
\hline \multirow{3}{*}{$\begin{array}{l}\text { Treatments } \\
\text { N-R }\end{array}$} & \multicolumn{9}{|c|}{ Plant height \pm SE $(\mathrm{cm})$} \\
\hline & \multicolumn{3}{|c|}{50 DAS } & \multicolumn{6}{|c|}{$100 \mathrm{DAS}$} \\
\hline & 9.61 & \pm & 0.35 & $*$ & 8.64 & \pm & 0.27 & $*$ & \\
\hline O-R & 7.09 & \pm & 0.33 & & 7.42 & \pm & 0.23 & & \\
\hline N-P & 9.67 & \pm & 0.61 & $*$ & 12.68 & \pm & 0.44 & n.s & $\dagger$ \\
\hline $\mathrm{O}-\mathrm{P}$ & 7.07 & \pm & 0.46 & & 11.31 & \pm & 0.61 & & $\dagger$ \\
\hline \multirow{2}{*}{ Treatments } & \multicolumn{9}{|c|}{ Shoot dry weight \pm SE (mg/pot) } \\
\hline & \multicolumn{3}{|c|}{50 DAS } & \multicolumn{4}{|c|}{100 DAS } & & \\
\hline N-R & 1.26 & \pm & 0.11 & $*$ & 1.00 & \pm & 0.08 & n.s & $\dagger$ \\
\hline O-R & 0.55 & \pm & 0.09 & & 0.81 & \pm & 0.02 & & \\
\hline N-P & 1.22 & \pm & 0.06 & $*$ & 3.81 & \pm & 0.13 & $*$ & $\dagger$ \\
\hline $\mathrm{O}-\mathrm{P}$ & 0.60 & \pm & 0.04 & & 2.27 & \pm & 0.14 & & $\dagger$ \\
\hline \multirow{2}{*}{ Treatments } & \multicolumn{9}{|c|}{ Root dry weight $\pm \mathrm{SE}$ (mg/pot) } \\
\hline & \multicolumn{3}{|c|}{$50 \mathrm{DAS}$} & \multicolumn{5}{|c|}{$100 \mathrm{DAS}$} & \\
\hline N-R & 0.24 & \pm & 0.03 & n.s & 0.34 & \pm & 0.03 & n.s & \\
\hline O-R & 0.16 & \pm & 0.03 & & 0.32 & \pm & 0.04 & & \\
\hline N-P & 0.25 & \pm & 0.04 & n.s & 0.53 & \pm & 0.01 & n.s & $\dagger$ \\
\hline $\mathrm{O}-\mathrm{P}$ & 0.15 & \pm & 0.03 & & 0.49 & \pm & 0.03 & & $\dagger$ \\
\hline
\end{tabular}

* Significant differences based on t-tests between non-contaminated and contaminated soil in each plot $(\mathrm{n}=12)$

$\dagger$ Significant differences based on t-tests between 50 DAS and 100 DAS in each plot $(\mathrm{n}=$ 12)

Refer to Table 2 for explanation of treatments.

SE: standard error; DAS: days after sowing

The mean plant height, shoot dry weight, and root dry weight of 12 plants are summarized in Table 3. Plant height with O-R treatment was significantly lower than that with N-R treatment by $26 \%$ and $14 \%$ at 50 and 100 DAS, respectively. Similarly, plant height with O-P treatment was lower than that with N-P treatment by $27 \%$ and $11 \%$ at 50 and 100 DAS, respectively. Shoot dry weight with O-R treatment was lower than that with N-R treatment by $56 \%$ and $19 \%$ at 50 and 100 DAS, respectively. Shoot dry weight with O- 
P treatment was lower than that with N-P treatment by $51 \%$ and $40 \%$ at 50 and 100 DAS, respectively. Root dry weights with O-R and O-P treatments were lower than with N-R treatment; however, there were no significant differences. Although plant height, shoot dry weight, and root dry weight in the P plots at 100 DAS were significantly higher than those at 50 DAS, no significant differences were found between 50 DAS and 100 DAS in the O$\mathrm{R}$ treatment.

Mean plant flowering numbers of 12 plants are shown in Table 4. Although no significant differences were found among treatments at $50 \mathrm{DAS}$, the flowering number in the O-P treatment was significantly lower than that in the N-P treatment at 100 DAS.

Table 4. Transition of plant height and dry weight of Zinnia hybrid 'Profusion White'

\begin{tabular}{lrlllrlll}
\hline \multirow{2}{*}{ Treatments } & \multicolumn{8}{c}{ Flowering number } \\
\cline { 2 - 9 } & \multicolumn{3}{c}{50 DAS } & \multicolumn{5}{c}{100 DAS } \\
\hline N-R & 1.00 & \pm & 0.41 & n.s & 0.00 & \pm & 0.00 & n.s \\
O-R & 0.00 & \pm & 0.00 & & 0.25 & \pm & 0.25 & \\
N-P & 1.00 & \pm & 0.41 & n.s & 10.25 & \pm & 1.11 & $*$ \\
O-P & 0.00 & \pm & 0.00 & & 6.25 & \pm & 0.63 & \\
\hline
\end{tabular}

* Significant differences based on t-tests between non-contaminated and contaminated soil in each plot $(\mathrm{n}=12)$

Refer to Table 2 for explanation of treatments.

DAS: days after sowing

Table 5. Transition of soil dehydrogenase activity (DHA)

\begin{tabular}{|c|c|c|c|c|c|c|c|c|}
\hline \multirow{3}{*}{$\begin{array}{c}\text { Treatments } \\
\text { N-E }\end{array}$} & \multicolumn{8}{|c|}{ Soil DHA \pm SE (mg INTF/g DW/h) } \\
\hline & \multicolumn{3}{|c|}{$50 \mathrm{DAS}$} & \multicolumn{5}{|c|}{100 DAS } \\
\hline & 4.15 & \pm & 0.35 & $b^{z}$ & 3.78 & \pm & 0.302 & $\mathrm{c}$ \\
\hline N-R & 6.57 & \pm & 0.358 & a & 5.46 & \pm & 0.39 & $\mathrm{~b}$ \\
\hline N-P & 7.27 & \pm & 0.629 & $\mathrm{a}$ & 7.55 & \pm & 0.13 & a \\
\hline $\mathrm{O}-\mathrm{E}$ & 6.90 & \pm & 0.732 & $\mathrm{~b}$ & 12.27 & \pm & 0.848 & $\mathrm{~b}$ \\
\hline $\mathrm{O}-\mathrm{R}$ & 13.85 & \pm & 1.868 & $\mathrm{a}$ & 17.67 & \pm & 1.064 & a \\
\hline $\mathrm{O}-\mathrm{P}$ & 14.17 & \pm & 1.183 & $\mathrm{a}$ & 20.18 & \pm & 1.816 & $\mathrm{a}$ \\
\hline
\end{tabular}

${ }^{z}$ Different letters denote significant differences at the 5\% level based on Tukey's multiple comparison test in each soil $(n=4)$

Refer to Table 2 for explanation of treatments.

INTF: iodo-nitrotetrazolium formazan; DW: dry weight; SE: standard error; DAS: days after sowing

The mean soil DHA values of four pots are shown in Table 5. Though soil DHA value at 100 DAS in the N-P treatment was higher (3\%) than that at 50 DAS, soil DHA decreased in the other two plots of non-contaminated soil. Soil DHA values at 100 DAS in the E, R, and $\mathrm{P}$ plots in contaminated soil were higher than those at 50 DAS by $78 \%, 28 \%$, and $42 \%$, respectively. Soil DHA values at both 50 and 100 DAS in O-R and O-P treatments were significantly higher than those in the O-E treatment. Values in the N-R and N-P treatments were significantly higher than in the N-E treatment. Soil DHA values at both 50 and 100 DAS in all plots in contaminated soil were higher than in all plots in non-contaminated soils. Though there was a significant difference in soil DHA values between the N-R and the N-P treatments at 100 DAS, there were no significant differences between the O-R and 
the O-P treatments at 50 and 100 DAS, and between the N-R and the N-P treatments at 50 DAS.

While soil TPH concentrations in all treatments at 50 DAS were significantly lower than at the start of the experiment, there were no significant differences between 50 and 100 DAS (Table 6).

Table 6. Transition of soil total petroleum hydrocarbon (TPH) concentration

\begin{tabular}{cccc}
\hline \multirow{2}{*}{ Treatments } & \multicolumn{3}{c}{ Soil TPH concentration \pm SE (mg diesel/kg soil) } \\
\cline { 2 - 4 } & 0 DAS & 50 DAS & $100 \mathrm{DAS}$ \\
\hline O-E & $33513 \pm 767 \mathrm{a}^{\mathrm{z}} \mathrm{A}^{\mathrm{y}}$ & $14275 \pm 1315 \mathrm{aB}$ & $13849 \pm 812 \mathrm{aB}$ \\
O-R & $33513 \pm 767 \mathrm{aA}$ & $14148 \pm 1012 \mathrm{aB}$ & $11607 \pm 184 \mathrm{bB}$ \\
O-P & $33513 \pm 767 \mathrm{aA}$ & $14818 \pm 1048 \mathrm{aB}$ & $11556 \pm 254 \mathrm{bB}$ \\
\hline
\end{tabular}

z Different lower case letters denote significant differences at the $5 \%$ level based on Tukey's multiple comparison test for days after sowing (DAS) $(n=4)$

y Different capital letters denote significant differences at the 5\% level based on Tukey's multiple comparison test for each treatment $(n=4)$

Refer to Table 2 for explanation of treatments.

SE: standard error

Removal rates from the initial TPH concentration at 50 DAS were 57\% (O-E treatment), $58 \%$ (O-R treatment), and 56\% (O-P treatment). There were no significant differences among treatments. Though removal rates from the initial TPH concentration at 100 DAS were significantly higher (7\%, O-R treatment; $10 \%$, O-P treatment) than removal rates from the initial TPH concentration at 50 DAS, there were no significant differences between 50 and 100 DAS. Removal rates from the initial TPH concentration at 100 DAS were $65 \%$ for the O-R treatment and $66 \%$ for the O-P treatment, significantly higher than for the O-E treatment (59\%). There were no significant differences between the O-R and O-P treatments.

\section{Discussion}

Mineral oil contains harmful components (e.g., polycyclic aromatic hydrocarbons) that adversely affect plants [9]. Mineral oil also has remarkable adverse effects on soil ecosystems and crops owing to its hydrophobic nature [9]. However, plant growth and stress responses vary with varying levels of oil contamination in the soil and differences among plant species $[10,11]$. We found that plant height and shoot dry weight in contaminated soil were lower than in non-contaminated soil. In contrast, there was no significant difference in root dry weight between contaminated soil and non-contaminated soil, so diesel oil mainly inhibits the growth of shoots in zinnia. While shoot dry weight in the N-R treatment at 100 DAS was significantly lower than at $50 \mathrm{DAS}$, there was no significant difference between 50 and 100 DAS in the O-R treatment. Soil TPH concentrations in the O-R treatment at 50 DAS was significantly lower than at the start of the experiment. Therefore, in the O-R treatment, growth inhibition may decreased with decreasing soil TPH concentration.

Flowering number in O-P treatment was significantly lower than in N-P treatment at 100 DAS. Z. hybrida 'Profusion White' is a flowering plant that forms flower buds at the apex of branches. In addition, plant height and shoot dry weight in O-P treatment at 100 
DAS were $11 \%$ and $40 \%$ lower than in N-P treatment. The number of flowers may decrease because branching did not occur in O-P treatment due to declines in growth.

Soil DHA values in R and P plots were significantly higher than in E plots. Plant root secretion and root cells become microbial nutrients and growth promoting substances and enhance microbial activity [12]. Soil TPH concentration showed an opposite trend to the concentration of soil DHA and was significantly lower in P and R plots than in E plots. Soil DHA increased in contaminated soils compared with non-contaminated soils, and DHA in contaminated soil tended to increase with increasing DAS. Previous studies have reported that petroleum components increase the activity of oil-degrading microorganisms [13, 14]. Degradation of diesel oil in soil would be promoted by the activity of degrading microorganisms enhanced by plant roots. At 100 DAS, while soil DHA in O-R and O-P treatments were significantly higher than in the O-E treatment, no significant difference was found between O-R and O-P treatments. Kubota et al. [15] reported that the type and amount of root exudates vary with different plants. The reason why no significant difference in soil DHA values was found between O-R and O-P treatments could be because in the O-R treatment, dead root cells remained in the soil when replanted, while in the O-P treatment, substances secreted by the plant roots after 50 DAS remained in the soil. Substances secreted by zinnia plant roots may therefore have the same effect on microorganism activity as dead root cells.

Soil TPH concentrations in O-R and O-P treatments at 100 DAS were significantly lower than in O-E treatment. There were no significant differences between O-R and O-P treatments throughout the study period. TPH removal rates from 50 to 100 DAS were significantly lower than those from 0 to 50 DASs. Previous studies have reported difficulties in biodegradability because of certain components that make up petroleum hydrocarbons $[16,17,20]$. Short chains have high degradability compared to long chains in aliphatic hydrocarbons [17]. In all treatments, degradable diesel oil components may degrade readily up to $50 \mathrm{DAS}$. At $50 \mathrm{DAS}$, plants in the O-R treatment were replanted but the residual amount of readily degradable components had already decreased. We conclude that replanting does not affect degradation. The high degradation effect observed during the initial growth period in our previous study [6] could be attributed to the degradation of several readily degradable components before replanting. The roots of zinnia therefore affect the activity of microorganisms in the rhizosphere throughout the entire growth period.

\section{Conclusion}

Previously, we demonstrated that the zinnia plant was effective for the phytoremediation of oil-contaminated soils and that it had a higher remediation effect during the initial growth period. Repeated planting of zinnia to maximize the initial growth period may enhance the remediation of contaminated soils. Higher oil degradation was observed in the O-R and O-P treatments than in the O-E treatment. O-P treatment involves cultivation without replanting, so may reduce labor and cost compared with O-R treatment. We conclude that replanting does not affect degradation and that it is appropriate to continue cultivating the same zinnia plants for phytoremediation.

\section{References}

1. F.I. Khan, T. Husain, R. Hejazi, J. Environ. Manage. 71, 95-122 (2004)

2. E. Kaimi, T. Mukaidani, S. Miyoshi, M. Tamaki, Environ. Exp. Bot. 55, 110-119 (2006) 
3. V.S. Cerqueira, M.C.R. Peralba, F.A.O. Camargo, F.M. Bento, Int. Biodeterior. Biodegradation 95, 338-345 (2014)

4. H. Ikeura, Y. Kawasaki, E. Kaimi, J. Nishiwaki, K. Noborio, M. Tamaki, Int. J. Phytorem. 18, 460-466 (2016)

5. E. Kaimi, T. Mukaidani, M. Tamaki, Plant Prod. Sci. 10, 105-111 (2007)

6. H. Ikeura, S. Ozawa, M. Tamaki, Ecology and Safety 10, 265-272 (2016)

7. K. Hayase, Experimental Methods in Soil Microbiology-New Edition. (Youken-dou, Tokyo, 1992)

8. The Geo-Environmental Protection Center, Guidelines against Oil Pollution by the Ministry of Environment. (The Chemical Daily Co., Ltd., Tokyo, 2006)

9. K.A. Reilley, M.K. Banks, A.P. Schwab, J. Environ. Qual. 25:212-219. (1996)

10. N. Merkl, R. Schultze-Kraft, C. Infante, Water Air Soil Pollut. 165, 195-209 (2005)

11. M. Hawrot-Paw, T. Bakowska, Environ. Protect. Eng. 40, 5-13 (2014)

12. S.D. Cunningham, T.A. Anderson, A.P. Schwab, F.C. Hsu, Adv. Agron. 56, 55-114 (1996)

13. K.E. Gerhardt, X.D. Huang, B.R. Glick, B.M. Greenberg, Plant. Sci. 176, 20-30 (2009)

14. Z. Cai, Q. Zhou, S. Peng, K. Li, J. Hazard. Mater. 183, 731-737 (2004)

15. M. Kubota, M. Hyakumachi, M. Miyazawa, J. Oleo Sci. 53, 207-210 (2004)

16. J. Tang, R. Wang, X. Niu, Q. Zhou, Soil Tillage Res. 110, 87-93 (2010)

17. Y. Jiang, K.J. Brassington, G. Prpich, G.I. Paton, K. T. Semple, S.J.T. Pollard, F. Coulon, Chemosphere 161, 300-307 (2016) 